\title{
Does Preoperative Positron Emission Tomography Help Delineate the Boost Volume After Oncoplastic Surgery for Breast Cancer?
}

\author{
Ayşe YILDIRIM ALTINOK, ${ }^{1}$ Mine DOYURAN, ${ }^{1}$ Mustafa ÇAĞLAR, ${ }^{1}$ Tansel ÇAKIR, ${ }^{2}$ Hilal ACAR, ${ }^{1}$ \\ Esra KÜÇÜKMORKOÇ, ${ }^{1}$ Nadir KÜÇÜK, ${ }^{1}$ Hale ÇAĞLAR, ${ }^{1}$ Tamer ATASEVER ${ }^{2}$
}

'Department of Radiation Oncology, Medipol University, İstanbul, Turkey

'Department of Nuclear Medicine, Medipol University, İstanbul, Turkey

\begin{abstract}
OBJECTIVE
The tumor bed within the breast shifts during oncoplastic surgery (OPS) for breast cancer (BC). Preoperative imagery is used to determine the boost volume (BV) for patients not implanted with surgical clips. This prospective study was conducted to geometrically compare BVs determined using preoperative imagery and BVs determined utilizing surgical clips.
\end{abstract}

\section{METHODS}

Patients diagnosed with BC were scanned using PET-CT during 2013-2015. Twenty patients who had undergone OPS but who did not have metastasis underwent CT prior to radiotherapy. Their preoperative images were fused with planning CT images. The tumor volume (CTVboost-pet), as determined from the preoperative PET-CT images, was contoured. Next, CTVboost-clips was determined using surgical clips. Geometric relationships between these two volumes were statistically compared.

\section{RESULTS}

Planar projections of CTVboost-pet and CTVboost-clips were evaluated. Displacements between CTVboost-pet and CTVboost-clips in the axial (XZ) and coronal (XY) planes were $1.17 \mathrm{~cm}(\mathrm{~min}-\max : 0.03-$ $3.64 \mathrm{~cm})$ and $1.67 \mathrm{~cm}$ (min-max: $0.38-4.14 \mathrm{~cm})$, respectively, and were statistically significant $(\mathrm{p}<0.001)$, whereas the displacement in the sagittal (YZ) plane was $1.07 \mathrm{~cm}$ (min-max: 0.04-4.45 cm) and was not significant $(\mathrm{p}>0.7)$.

\section{CONCLUSION}

Preoperative imaging alone was not reliable when determining the BV in patients who had undergone OPS and had no clips. Large PTV margins can be an option to overcome this issue. Surgical clips need to be inserted during OPS.

Keywords: Boost volume; Breast cancer; Oncoplastic surgery; PET-CT; Radiotherapy.

Copyright @ 2017, Turkish Society for Radiation Oncology

\section{Introduction}

The importance of boosting during adjuvant radiotherapy (RT) for breast cancer, particularly in women un- der the age of 60 years, has been validated by the "Randomized Phase III study published by the EORTC.[1] This study has confirmed that the administration of an additional dosage of $16 \mathrm{~Gy}$ to the predetermined boost 


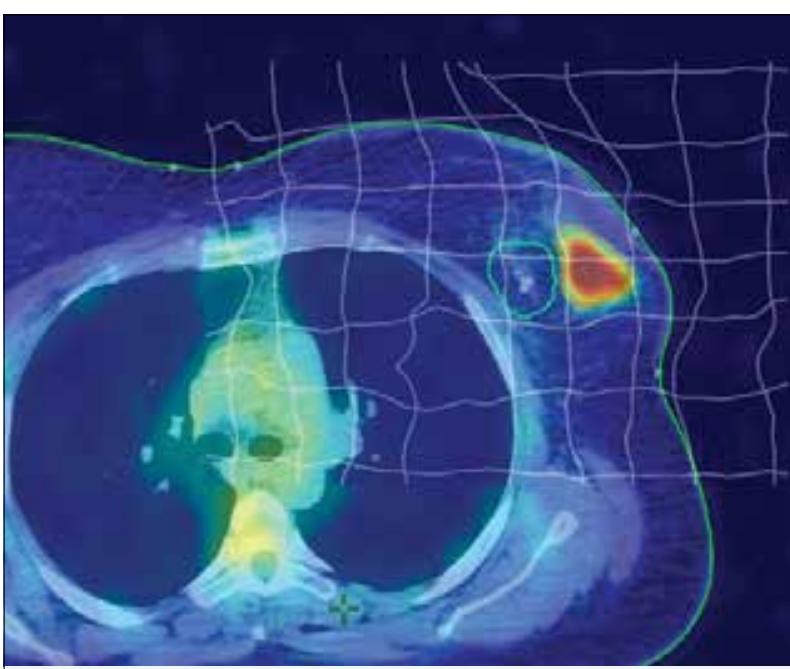

Fig. 1. Deformable fusion image obtained by superposing pre-op PET-CT and planning CT images using TPS.

volume (BV) increases the local control rate. Besides, a recent meta-analysis conducted by the EBCTCG suggests that each four local controls provides one survival .[2]

In recent years, oncoplastic surgery (OPS) for breast cancer to obtain cosmetic reasons is being increasingly performed. Techniques used during these operations require tumors to be removed with larger margins; the tumor cavity is shifted to a different quadrant using various flap sliding methods.[3-5]

Surgical clips, when implanted during surgery, and preoperative images (when surgical clips are not present) are used to determine the volume for the abovementioned additional boost.[6-8] When determining the $\mathrm{BV}$, radiation oncologists add a certain safety margin all around the volume outlined by clips.[9-11] When surgical clips are not available, preoperative images and the location of a postoperative seroma are used to estimate the BV. This estimated volume, even if it is established highly subjectively, used to be acceptable in conventional tumor removal surgeries. A methodical approach to reduce inter- and intraobserver variability in clinical practice has been put forward. [12] However, when the tumor bed is moved from its original quadrant to a different location during tissue rearrangement for cosmetic reasons following excision in OPS, the plausibility of using preoperative images must be questioned.

In this prospective study, the geometries of BVs determined using surgical clips and those predicted using preoperative PET-CT images were compared. Our

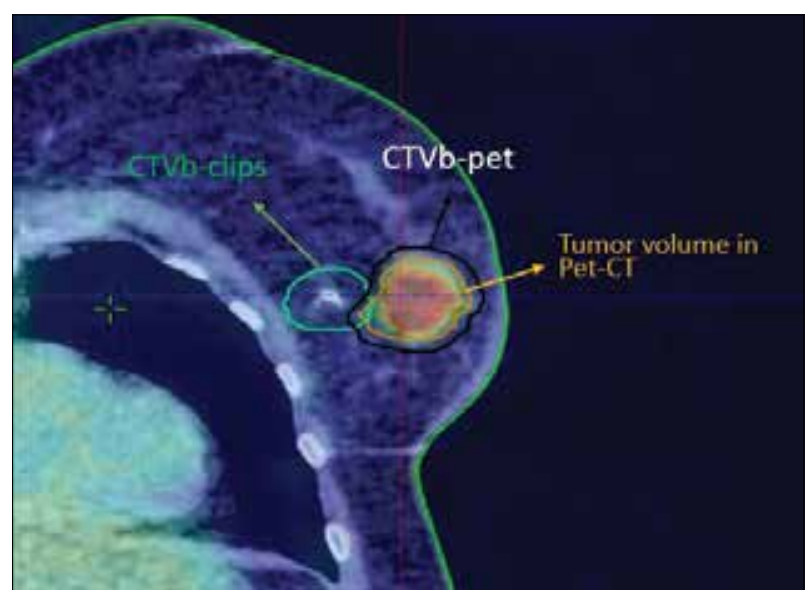

Fig. 2. Contouring of CTVb-pet and CTVb-clip.

aim was to question the suitability of using preoperative images to determine the BV of patients who have undergone OPS for breast cancer.

\section{Materials and Methods}

After receiving approval from the ethical committee and consent from the patients, between 2013 and 2015 , breast cancer patients who had undergone OPS and RT and who had undergone PET-CT scans for the diagnostic workup were included. During PET-CT, the patients are laid on the breast board with their ipsilateral arms supinating as in the RT position but standard PET-CT imaging procedure was performed. Patients who were diagnosed as having metastasis after imaging were excluded. Patients diagnosed with local and local advanced tumors were registered and redirected to undergo surgery. Twenty of these patients who had undergone OPS and completed adjuvant chemotherapy and who were under 60 years of age were included. The patients were placed on breast boards as in their position for CT with 2-mm slices prior to planning for RT. Images were transferred to the treatment planning system (TPS). Preoperative PET-CT images were also imported to the TPS and merged using the available software (Eclips 13.0) (Fig.-1).

Planning CT and preoperative PET-CT images were superposed using the rigid fusion method based on "user origins," and breast tissue was added to the image using the deformable fusion method. As the final step, the three-dimensional common point was chosen as the origin and the $\mathrm{x}-, \mathrm{y}-$, and $\mathrm{z}$-axes for both images were accordingly assigned.

In the first step, the tumor volume, as determined from the preoperative PET-CT images, was contoured 


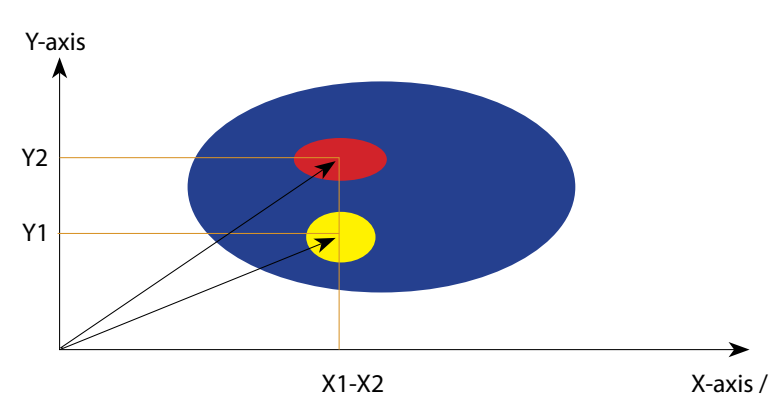

Fig. 3. Evaluation of CTVboost-pet and CTVboost-clips in the coronal (XY) section. Demonstration of a case where the volumes have the same $\mathrm{X}$-coordinate but different Y-coordinates, i.e., a displacement vector exists.

and pathological surgical borders were added; this volume was designated as CTVboost-pet in the following analysis. In the second step, surgical clips (four each) were marked as a volume CTVboost-clips (Fig. 2).

To determine the geometric shift between CTVboostpet and CTVboost-clips, the center of mass for both was calculated and plotted (Fig. 3). The three-dimensional shift between the two was then broken into its two-dimensional components for easier visualization and assessment: XY (coronal), XZ (axial), and YZ (sagittal).

The geometric shift calculated for all three axes was then analyzed using Student's t-test.

\section{Results}

Results from the 20 patients who had undergone OPS with adjuvant RT were evaluated. The mean geometric shift of the BVs in the axial plane was $1.17 \mathrm{~cm}$ (minmax: $0.03-3.64 \mathrm{~cm}$ ). In the coronal plane, the mean shift was $1.67 \mathrm{~cm}$ (min-max: $0.38-4.14 \mathrm{~cm}$ ). The shifts in these two planes were determined to be statistically significant (with $\mathrm{p}<0.001$ ), which means that the preoperative tumor volume and post-OPS BV were in different locations in the axial and coronal planes. The geometric shift in the sagittal plane was $1.07 \mathrm{~cm}$ (minmax: $0.04-4.45 \mathrm{~cm}$ ). A statistically significant shift in the sagittal plane was not seen ( $p>0.7)$. All displacements between CTVboost-pet and CTVboost-clips were $>1 \mathrm{~cm}$.

\section{Discussion}

The results of the current study have shown that there is a notable shift in BVs and their center of masses (in the coronal and axial planes) when the preoperative tumor volume and volume defined by clips are compared.

Number and placement technique during OPS of clips has been defined.[13,14] Alco et al have shown that CTV BV dosage conformities change vary with the number of clips.[15] However, Kirwan et al have found that clips are not implanted for more than one-third of patients, in spite of benefits that have been demonstrated.[16] In cases where clips are not present, preoperative imagery is examined to determine the BV. The use of breast ultrasound and breast MR is not very appropriate for CT of RT planning due to the positions of the patient and breast. PET-CT and thoracic CT images obtained during staging present a better platform for comparison. Currently, there are limited data on such a comparison.

In a study assessing BV s obtained from preoperative and planning tomographies, the authors have reported that a minimum of three clips should be placed during OPS for accurate postoperative BV determination. [17] The authors also pointed out that the volume of tissue removed during OPS is higher than that removed during other surgical methods; therefore, the BV should be kept to a minimum to not diminish cosmetic outcomes. In another study, it has been of stated that preoperative PET-CT images processed via deformable fusion can be used for RT planning. [18] However, the surgical methods were not mentioned; hence, their relevance to OPS is unclear. Therefore, only breast cancer patients with PET-CT images were included in the present study.

Clips have to be implanted in a certain order to facilitate BV generation. $[19,20]$ Previous studies have shown that clips do not always cover the tumor bed and the postoperative seroma; in some cases, the BV spreads out of the boundaries defined by clips.[21] While inclusion of the seroma along with the clips, therefore an increased BV for conventional surgery may be acceptable, the increased BV due to more extensive tissue removal and quadrant shifts in OPS may affect the accuracy of BV and the desired cosmetic outcomes. The cosmetic outcome of an increased BV needs to be further investigated.

Rigid fusion of registries is used where anatomical changes are limited or for superposing fixed tissue images. In cases where the tissue is removed, relocated, and/or altered due to surgical or treatment procedures or positional differences, deformable fusion techniques produce more reliable and effective results. This technique also provides better CTV definitions in cases where external contours are altered.[22] Therefore, in 
our study, rigid fusion is used for superposing "user origins" and deformable fusion is used for superposing the breast portion of preoperative PET-CT and planning CT images.

Schaverian et al published a review on this topic in 2013 and evaluated a total of 24 studies regarding the determination of BV during OPS. It was reported that clips were used to determine the BV in 9 of these studies, but the basis for volume determination was not mentioned in the other studies. Their concern was in using only surgical clips for volume determination after OPS where the primary tumor volume is displaced. They emphasized the fact that OPS is more frequently performed on young patients with large tumors and the importance of coordination between the surgeon and radiation oncologist to obtain the most effective outcomes for boost treatment, particularly in this patient segment who will benefit the most.[23]

\section{Conclusion}

When the planar coordinates of CTVboost-pet and CTVboost-clips were evaluated, displacements in the axial and coronal planes were statistically significant and were $>1 \mathrm{~cm}$. On the other hand, displacements in the sagittal plane were not statistically significant.

These results suggest that the use of preoperative tumor volume, which is the current basis for treatment, is not very accurate for determining the $\mathrm{BV}$ in patients who have undergone OPS. Objective criteria and methods need to be established for guidance. Until a golden standard is established through research and validation, the BV should always be determined taking all available information into account and larger PTV margins might be suitable for patients who have undergone OPS. Additionally, for patients who have undergone OPS without surgical clips on the tumor bed, using PTV margins of more than $1 \mathrm{~cm}$ may be reliable for overcoming this issue.

\section{Disclosures Statement}

The authors declare no conflicts of interest.

Acknowledgments: The authors have no fundings or conflicts of interest to disclose.

Ethics Committee Approval: This study was conducted inaccordance with local ethical rules.

Peer-review: Externally peer-reviewed.
Conflict of Interest: None declared.

Authorship contributions: Concept - A. Y. A; Design - A. Y. A; Supervision - T. A; Materials - A. Y. A, H. Ç, T. Ç; Data collection \&/or processing - A. Y. A, T. Ç; Analysis and/ or interpretation - M. D, M. Ç, H. A, E. K, N. K; Literature search - A. Y. A; Writing - A. Y. A, M. D, M. Ç; Critical review - T. A.

\section{References}

1. Bartelink H, Horiot JC, Poortmans PM, Struikmans $\mathrm{H}$, Van den Bogaert W, Fourquet A, et al. Impact of a higher radiation dose on local control and survival in breast-conserving therapy of early breast cancer: 10-year results of the randomized boost versus no boost EORTC 22881-10882 trial. J Clin Oncol 2007;25(22):3259-65.

2. Early Breast Cancer Trialists' Collaborative Group (EBCTCG), Darby S, McGale P, Correa C, Taylor C, Arriagada R, Clarke M, et al. Effect of radiotherapy after breast-conserving surgery on 10-year recurrence and 15-year breast cancer death: meta-analysis of individual patient data for 10,801 women in 17 randomised trials. Lancet 2011;378(9804):1707-16.

3. Berry MG, Fitoussi AD, Curnier A, Couturaud B, Salmon RJ. Oncoplastic breast surgery: a review and systematic approach. J Plast Reconstr Aesthet Surg 2010;63(8):1233-43.

4. Clough KB, Kaufman GJ, Nos C, Buccimazza I, Sarfati IM. Improving breast cancer surgery: a classification and quadrant per quadrant atlas for oncoplastic surgery. Ann Surg Oncol 2010;17(5):1375-91.

5. Kaur N, Petit JY, Rietjens M, Maffini F, Luini A, Gatti $\mathrm{G}$, et al. Comparative study of surgical margins in oncoplastic surgery and quadrantectomy in breast cancer. Ann Surg Oncol 2005;12(7):539-45.

6. Harrington KJ, Harrison M, Bayle P, Evans K, Dunn $\mathrm{PA}$, Lambert HE, et al. Surgical clips in planning the electron boost in breast cancer: a qualitative and quantitative evaluation. Int J Radiat Oncol Biol Phys 1996;34(3):579-84.

7. Dzhugashvili M, Pichenot C, Dunant A, Balleyguier C, Delaloge S, Mathieu MC, et al. Surgical clips assist in the visualization of the lumpectomy cavity in three-dimensional conformal accelerated partial-breast irradiation. Int J Radiat Oncol Biol Phys 2010;76(5):1320-4.

8. Coles CE, Wilson CB, Cumming J, Benson JR, Forouhi P, Wilkinson JS, et al. Titanium clip placement to allow accurate tumour bed localisation following breast conserving surgery: audit on behalf of the IMPORT Trial Management Group. Eur J Surg Oncol 
2009;35(6):578-82.

9. Offersen BV, Boersma LJ, Kirkove C, Hol S, Aznar MC, Biete Sola A, et al. ESTRO consensus guideline on target volume delineation for elective radiation therapy of early stage breast cancer. Radiother Oncol 2015;114(1):3-10.

10. Boersma LJ, Janssen T, Elkhuizen PH, Poortmans P, van der Sangen M, Scholten AN, et al. Reducing interobserver variation of boost-CTV delineation in breast conserving radiation therapy using a pre-operative $\mathrm{CT}$ and delineation guidelines. Radiother Oncol 2012;103(2):178-82.

11.https://www.rtog.org/CoreLab/ContouringAtlases/ BreastCancerAtlas.aspx. Accessed Dec 6, 2017.

12. Benda RK, Yasuda G, Sethi A, Gabram SG, Hinerman RW, Mendenhall NP. Breast boost: are we missing the target? Cancer 2003;97(4):905-9.

13. Strnad V, Hannoun-Levi JM, Guinot JL, Lössl K, Kauer-Dorner D, Resch A, et al. Recommendations from GEC ESTRO Breast Cancer Working Group (I): Target definition and target delineation for accelerated or boost Partial Breast Irradiation using multicatheter interstitial brachytherapy after breast conserving closed cavity surgery. Radiother Oncol 2015;115(3):342-8.

14. Major T, Gutiérrez C, Guix B, van Limbergen E, Strnad V, Polgár C; Breast Cancer Working Group of GECESTRO. Recommendations from GEC ESTRO Breast Cancer Working Group (II): Target definition and target delineation for accelerated or boost partial breast irradiation using multicatheter interstitial brachytherapy after breast conserving open cavity surgery. Radiother Oncol 2016;118(1):199-204.

15. Alço G, Igdem S, Okkan S, Dincer M, Sarsenov D, Ilgun AS, et al. Replacement of the tumor bed following oncoplastic breast-conserving surgery with immediate latissimus dorsi mini-flap. Mol Clin Oncol 2016;5(4):365-71.
16. Kirwan CC, Al Sarakbi W, Loncaster J, Chan HY, Thompson AM, Wishart GC. Tumour bed clip localisation for targeted breast radiotherapy: compliance is proportional to trial-related research activity: tumour bed clip localisation in breast radiotherapy. Eur J Surg Oncol 2014;40(2):158-62.

17. Furet E, Peurien D, Fournier-Bidoz N, Servois V, Reyal F, Fourquet A, et al. Plastic surgery for breast conservation therapy: how to define the volume of the tumor bed for the boost? Eur J Surg Oncol 2014;40(7):830-4.

18. Cho O, Chun M, Oh YT, Kim MH, Park HJ, Heo JS, et al. Can initial diagnostic PET-CT aid to localize tumor bed in breast cancer radiotherapy: feasibility study using deformable image registration. Radiat Oncol 2013;8:163.

19. Weed DW, Yan D, Martinez AA, Vicini FA, Wilkinson TJ, Wong J. The validity of surgical clips as a radiographic surrogate for the lumpectomy cavity in imageguided accelerated partial breast irradiation. Int J Radiat Oncol Biol Phys 2004;60(2):484-92.

20. Kirby AN, Jena R, Harris EJ, Evans PM, Crowley C, Gregory DL, et al. Tumour bed delineation for partial breast/breast boost radiotherapy: what is the optimal number of implanted markers? Radiother Oncol 2013;106(2):231-5.

21. Yang Z, Chen J, Hu W, Pan Z, Cai G, Yu X, et al. Planning the breast boost: how accurately do surgical clips represent the CT seroma? Radiother Oncol 2010;97(3):530-4.

22. Kirova YM, Servois V, Reyal F, Peurien D, Fourquet A, Fournier-Bidoz N. Use of deformable image fusion to allow better definition of tumor bed boost volume after oncoplastic breast surgery. Surg Oncol 2011;20(2):e123-5.

23. Schaverien MV, Stallard S, Dodwell D, Doughty JC. Use of boost radiotherapy in oncoplastic breast-conserving surgery - a systematic review. Eur J Surg Oncol 2013;39(11):1179-85. 